\title{
Synthesis and performance evaluation of a new kind of gel used as water shutoff agent
}

\author{
Lei Zhang ${ }^{1,2} \cdot$ Chunsheng Pu ${ }^{1,2} \cdot$ Liming Zheng ${ }^{1,2} \cdot$ Xiaoyu Gu ${ }^{1,2}$
}

Received: 2 March 2015/Accepted: 2 August 2015/Published online: 13 August 2015

(c) The Author(s) 2015. This article is published with open access at Springerlink.com

\begin{abstract}
In this paper, a kind of modified cellulose as a raw material of a water-based gel is studied systematically. Its migration performance is good and its solution is Newtonian fluid in porous medium. And more importantly, a water-based gel is synthesized with modified cellulose, acrylamide, $N, N^{\prime}$-methylene-bisacrylamide and persulphate. An appropriate formula of a gel is $0.8 \mathrm{wt} \%$ modified cellulose, $2 \mathrm{wt} \%$ acrylamide, $0.1 \mathrm{wt} \%$ cross-linking agent and $0.05 \mathrm{wt} \%$ initiator. The initial viscosity of this gelling solution is $72 \mathrm{mPa} s$ and the gelation time is $15 \mathrm{~h}$ at $70{ }^{\circ} \mathrm{C}$. After gelation, it is a strong gel and the elasticity is more outstanding than the viscosity. Its applied range in formation environment is the temperature of $60-90{ }^{\circ} \mathrm{C}$, the salinity of $0-100 \mathrm{~g} / \mathrm{L}$ and the $\mathrm{pH}$ value of $6-9$. The experimental results show that the gel system can be better applied to conformance control of the heterogeneity reservoir.
\end{abstract}

Keywords Modified cellulose · Graft copolymerization · Conformance control $\cdot$ Strong gel

Lei Zhang

zhangshishishi.188@163.com

1 China University of Petroleum (East China), Institute of Petroleum Engineering, Qingdao 266580, China

2 China University of Petroleum (East China), Research Center of Physical-Chemical Engineering and Technology on the Development of Complex Reservoirs, Qingdao 266580, China

\section{Introduction}

Conformance control technology has the benefit of increasing oil production and decreasing water cut, it has always been the research object of petroleum engineers (Liu et al. 2010). Especially in China, more and more oilfields are entering into the high water cut stage. So the technology plays an increasingly important role in the development of these oilfields. The successful key of conformance control technology is the chemical agents with efficient, cheap and environmentally friendly. Although it has been for decades for researching the agents (Vossoughi 2000; Dai et al. 2010), the success ratio of operation and economic benefit needs to be further improved. Therefore, it is necessary to develop new chemical agents with excellent performance and low cost.

In situ cross-linking polymer gel was widely used for water plugging in oilfield production, and a good result was achieved (Tang et al. 1996). This technology is that acrylamide, methylene diacrylamide and initiator were injected into the formation to form a high strength gel by in situ polymerization. The two most typical were "K-trol" and "TP system", which were developed by Halliburton company in USA and PetroChina Exploration and Development Research Institute, respectively (Vossoughi 2000; Li 1988). The initial viscosity of the gelling solution was approximate $2 \mathrm{mPa}$, which was almost equal to the viscosity of water, so that it had good pumping capability. A successful application of the technology was in Lick Creek oilfield (Woods et al. 1986). However, the technology had obvious flaw (Jia and Pu 2013): (1) The gelling solution was easy to be diluted by formation water and the reducing agents in the formation water could make the initiator lose efficacy; (2) The gelling solutions with low viscosity were easy to enter into low permeability layer to greatly lead to 
wrong plugging; (3) The gelation time was short so that the technology only plugged the near-wellbore area. So the application of this technology was limited due to these unfavorable factors.

In order to prevent the formation water from diluting the forefront of the gelling solution, Tang et al. (1997) developed the pre-pad fluid of sulfite to preprocess the layer on the basis of the technology of in situ cross-linking polymer gel. In order to significantly improve the cross-linking time and the temperature resistance, $\mathrm{Pu}$ et al. (1997) introduced high temperature resistant monomer and low-grade aldehyde into the in situ cross-linking gel system. The result was that the crosslinking time was more than $20 \mathrm{~h}$ and the resistance temperature was more than $120{ }^{\circ} \mathrm{C}$. Although the gel performance was improved, the amount of acrylamide monomer used in the gel system is more than $5 \%$. So its application was limited due to the high cost. By means of the idea of acid causing crosslinking reaction, Hou and Yue (2010) developed a plugging agent to control the gas channeling for $\mathrm{CO}_{2}$ flooding. Its composition was $2 \%$ acrylamide monomer and $5 \%$ sodium silicate. Although this gel system sharply reduced the amount of acrylamide monomer, the mechanical strength was greatly reduced. Therefore, development of new in situ cross-linking polymer gel with low cost and high strength for conformance control is very significant.

It is generally known that the cellulose, which is a green renewable resource and widely existing in nature, is an important raw material in the human production and living. Its structure is formed by D-glucopyranose ring connected with each other by $\beta-1,4$-glucoside bond with $\mathrm{C} 1$ chair conformation so that the cellulose can be grafted with different functional monomers to form copolymer with different performance. However, the grafting reaction of the cellulose is difficult because the hydroxyls of the cellulose are sealed due to the tight crystal structure (Liao et al. 2002; Ren et al. 2004). Since the 1960s, the domestic and foreign researchers have done a lot of work in cellulose modification. Pan et al. (1999) carried out extensive research on the grafting reaction of superfine cellulose and alkene monomers. Zhang et al. (2014) studied the chemical modification of cellulose by in situ reactive extrusion with several chemicals such as urea, phthalic anhydride (PA), maleic anhydride (MA) and butyl glycidyl ether (BGE). Thakur et al. (2013) studied the synthesis, characterization and evaluation of the graft copolymers of cellulose. They found that the graft copolymers are more moisture resistant and better thermal resistance. Tehrani and Neysi (2013) investigated the surface modification of the cellulose nanowhisker by grafting with 2-ethyl-2-oxazoline. And Peltzer et al. (2014) also investigated the surface modification of cellulose nanocrystals by grafting with poly (lactic acid). However, it has not been reported to the application and research of conformance control and water shutoff with modified cellulose in the oilfield production. In this paper, modified cellulose and alkene monomer are taken as raw materials to synthesize a gel used as water shutoff agent. And the synthesis conditions of the gel are investigated systematically.

\section{Experiment}

\section{Experimental materials and equipment}

Modified cellulose is obtained from Wang'erxin building materials factory of Jinzhou in China. Its molecular weight is $11 \times 10^{4}$ and the particles (around $3 \mu \mathrm{m}$ in diameter) can expand 5-6 times in distilled water. Acrylamide, $N, N^{\prime}$ methylene- bisacrylamide, ammonium hydroxide, persulphate, $\mathrm{CaCl}_{2}, \mathrm{MgCl}_{2}, \mathrm{NaCl}$, are all analytically pure and are obtained from Beijing chemical reagents company. Water used in the experiments is all distilled water. The artificial cores with the size of $4.5 \times 4.5 \times 30 \mathrm{~cm}^{3}$ in the experiments are obtained from Research Institute of Exploration and Development of Daqing Oilfield in China. The equipment of physical simulation experiment and operation methods is shown in the 18th references (Dai et al. 2011). The viscosity is tested by Brookfield viscometer, and the shear rate is 7.34/s. The visco-elasticity of the gel is tested by RS-600 rheometer.

The composition of simulated formation water with $50 \mathrm{~g} / \mathrm{L}$ salinity contains $15 \mathrm{~g} / \mathrm{L} \mathrm{CaCl}_{2}, 10 \mathrm{~g} / \mathrm{L} \mathrm{MgCl}_{2}$, $25 \mathrm{~g} / \mathrm{L} \mathrm{NaCl}$. The composition of simulated formation water with $100 \mathrm{~g} / \mathrm{L}$ salinity contains $30 \mathrm{~g} / \mathrm{L} \mathrm{CaCl}_{2}, 20 \mathrm{~g} / \mathrm{L}$ $\mathrm{MgCl}_{2}, 50 \mathrm{~g} / \mathrm{L} \mathrm{NaCl}$; The composition of simulated formation water with $150 \mathrm{~g} / \mathrm{L}$ salinity contains $45 \mathrm{~g} / \mathrm{L} \mathrm{CaCl}_{2}$, $30 \mathrm{~g} / \mathrm{L} \mathrm{MgCl}_{2}, 75 \mathrm{~g} / \mathrm{L} \mathrm{NaCl}$.

\section{Experiment method}

\section{Performance test of modified cellulose aqueous solution}

Firstly, the relationship of the viscosity and the mass concentration of the modified cellulose aqueous solution is tested by Brookfield Viscometer. Secondly, the rheological property of the modified cellulose aqueous solution is tested by RS-600 rheometer. Finally, the injection performance and residual resistance coefficient of the modified cellulose aqueous solution are tested to evaluate the migration performance in porous media by physical simulation experiment.

\section{Bottle test experiments}

In the experiments, the gel is synthesized with the main agents, cross-linking agent and initiator. The main agents are modified cellulose and acrylamide. The cross-linking 
agent is $N^{\prime}, N$-methylene double acrylamide. The initiator is persulfate. The experiment temperature is $70{ }^{\circ} \mathrm{C}$. The goal of this experiment is to study the effect of each component on the viscosity of the gel and optimize an appropriate formula of the gel by adjusting the proportion of four components in distilled water and observing the process of gelation (Yamada et al. 2014).

\section{Evaluation experiment of gel performance}

Firstly, the adaptability of the gel with the appropriate formula to the environment is evaluated by investigating the viscosity and the gelation characteristics under different temperature, salinity and $\mathrm{pH}$. Secondly, the visco-elasticity of the gel with the appropriate formula is tested. Finally, the breakthrough pressure and plugging performance of the gel with the appropriate formula are tested by physical simulation experiment under $70{ }^{\circ} \mathrm{C}$.

\section{Analysis of gelation reaction principles}

The structure of the cellulose is shown in Fig. 1. From Fig. 1, it can be observed that the carbon atoms, which are in the hydroxymethyl in the structure unit of cellulose, are as the starting point of the graft copolymerization to react with acrylamide under the action of free radicals to form macromolecules with a two dimensional structure. Then the macromolecules react with the cross-linking agent to form a gel with three-dimensional network structures, which are shown in Fig. 2. In the Fig. 2, Cell- $\mathrm{CH}_{2}-\mathrm{O}-$ is cellulose. $R_{1}, R_{2}, R_{3}$, all can be the chain of cellulose, the chain of acrylamide or the chain of graft copolymer of cellulose and acrylamide (Yamada et al. 2014).

\section{The results and discussion}

\section{The performance of modified cellulose aqueous solution}

The molecular weight of the modified cellulose is considerably higher than that of acrylamide monomer, so the initial performance of the gelling solution mainly depends on the amount of modified cellulose. Thus, it can characterize the performance of the gelling solution by analyzing the performance of the modified cellulose solution.

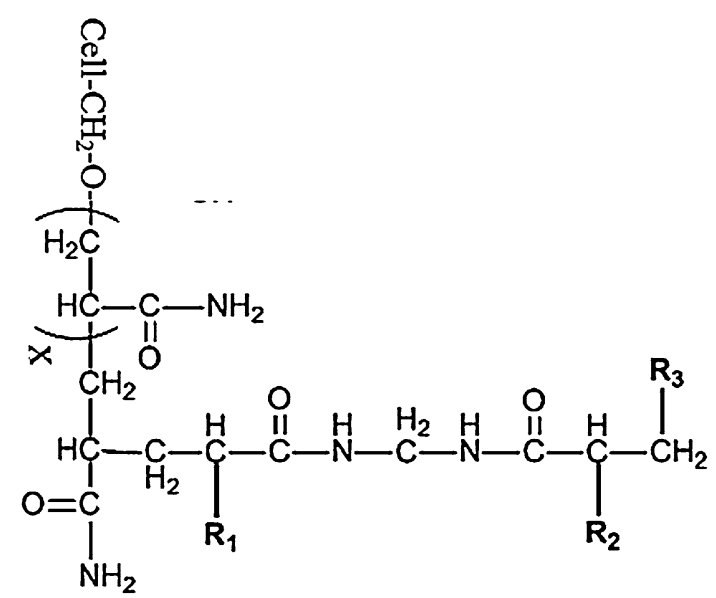

Fig. 2 The three- dimensional network structure of the gel

The relationship of the viscosity and the mass concentration of the modified cellulose solution

In the past, cellulose was widely used as a thickener in the oilfield production. Its aqueous solution with low mass concentration has a relatively high viscosity. This is because a mass of strong hydrogen bonding force and hydrogen bond network exists in its intermolecular and intramolecular to make its aqueous solution with high viscosity. However, the physical and chemical properties of the cellulose can be greatly changed by modification. Based on the mechanism of conformance control, it requires that the modified cellulose can be easily grafted with other vinyl monomer and the initial viscosity of its solution is low.

The dissolution time is less than 2 min when $1 \mathrm{~g}$ of modified cellulose is added into $100 \mathrm{~mL}$ of distilled water. The relationship of the viscosity and the mass concentration of the modified cellulose solution is shown in Fig. 3. From Fig. 3, it can be observed that the viscosity is less than $100 \mathrm{mPa}$ s when the mass concentration is lower than $1 \mathrm{wt} \%$. It shows that the viscosity of modified cellulose solution is low. So the modified cellulose aqueous solution can be easily pumped into high permeability layer when it is in a certain range of concentration.

\section{The rheological property of modified cellulose solution}

The $0.8 \mathrm{wt} \%$ modified cellulose solution is taken as the tested object. Its rheological property is shown in Fig. 4. From Fig. 4, it can be observed that the relationship of the
Fig. 1 The structure of cellulose

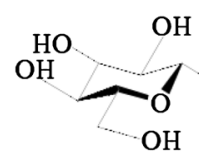

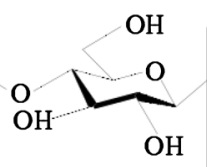

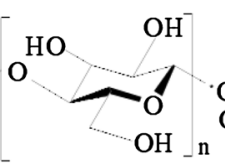




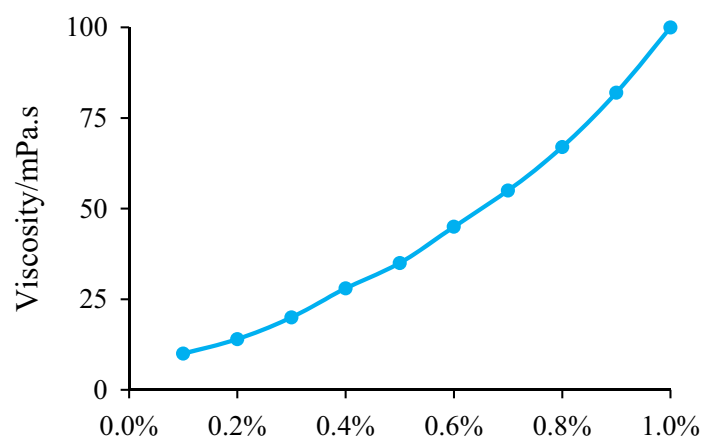

Mass concentration of modified cellulose

Fig. 3 The relationship of the viscosity and the mass concentration of modified cellulose solution

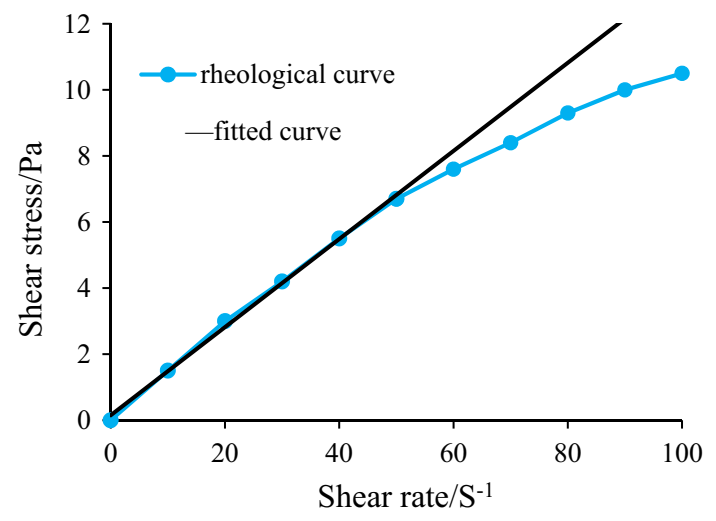

Fig. 4 The rheological curve of 0.8 wt $\%$ modified cellulose solution

shear stress and the shear rate is linear when the shear rate is less than 50/s. In the actual oil reservoir, the shear rate is at around 7.34/s which is much smaller than 50/s. Therefore, the flowing discipline of modified cellulose solution in the porous medium is basically accord with Darcy's law.

\section{The migration performance of modified cellulose solution} in porous media

In the core flow experiment, the injection rate is $2 \mathrm{~cm}^{3} /$ min to ensure that the fluid flow is in accord with Darcy's law. Other experimental parameters are shown in Table 1. From Table 1, it can be observed that the permeability is $0.3 \mu \mathrm{m}^{2}$ which is close to the lower limit of medium-high permeability reservoir. Therefore, the core flow experiment can reflect the migration performance of the modified cellulose in porous media with medium-high

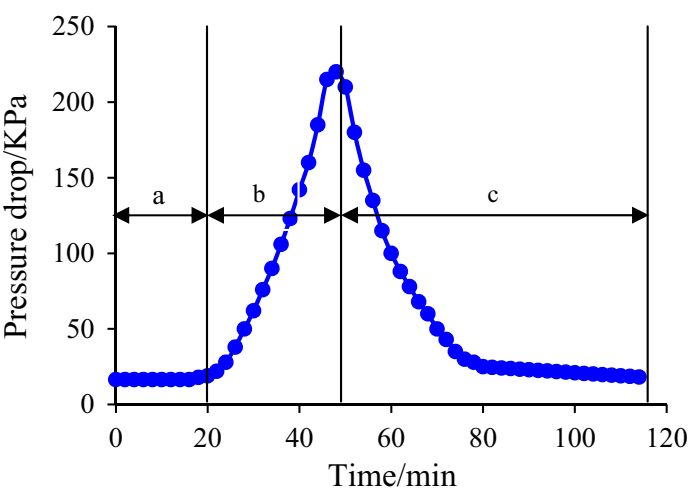

Fig. 5 The curve of pressure drop across the core of $0.8 \mathrm{wt} \%$ modified cellulose solution ( $a$ water flooding; $b$ injection $0.2 \mathrm{PV}$ modified cellulose solution; $c$ subsequent waterflooding)

permeability. The viscosity of $0.8 \mathrm{wt} \%$ modified cellulose aqueous solution is $72 \mathrm{mPa}$ s. The result of core flow experiment is shown in Fig. 5. From Fig. 5, it can be observed that the flow resistance of modified cellulose in porous media is low. The pressure drop across the core of primary water flooding is stable at $16.5 \mathrm{kPa}$. When turning to inject $0.2 \mathrm{PV}$ modified cellulose aqueous solution, the pressure drop has a certain degree of increase due to the increase in viscosity. But the increment extent of the pressure drop is much smaller than that of the viscosity. And in the stage of subsequent water flooding, the pressure drop can quickly fall to $17.4 \mathrm{kPa}$ which is close to that of the primary water flooding. It shows that the cellulose particles can smoothly through the pore throat of the rock to easily enter into the deep formation. The conclusion is that the modified cellulose solution has good migration ability in porous media.

\section{Formula optimization of the gel}

The effect of the main agents on the performance of the gel

The concentration of cross-linking agent and initiator is 0.1 and $0.05 \mathrm{wt} \%$, respectively. Whether the gelling solution can be gelled is observed by bottle tests and the viscosity of the gels after gelation is tested by Brookfield viscometer. The experimental results are shown in Table 2. From Table 2, it can be observed that the gelling solution cannot be gelled even if the concentration of acrylamide is high when the concentration of modification cellulose is less than $0.6 \mathrm{wt} \%$. Because when the concentration of

Table 1 Parameters of core flow experiment of modified cellulose solution

\begin{tabular}{llll}
\hline Temperature $/{ }^{\circ} \mathrm{C}$ & Core permeability $/ \mu \mathrm{m}^{2}$ & Core porosity $/ \%$ & Injection fluid \\
\hline 70 & 0.3 & 22.6 & Water +0.2 PV 0.8 wt $\%$ modified cellulose solution + water \\
\hline
\end{tabular}


Table 2 The viscosity of the gelling solution after gelation under different mass concentration of the main agents

\begin{tabular}{|c|c|c|c|c|c|c|}
\hline Acrylamidemodified cellulose (wt\%) & $0.5 \mathrm{wt} \%(\mathrm{mPa} \mathrm{s})$ & $1 \mathrm{wt} \%(\mathrm{mPa} \mathrm{s})$ & $1.5 \mathrm{wt} \%(\mathrm{mPa} \mathrm{s})$ & $2 \mathrm{wt} \%(\mathrm{mPa} \mathrm{s})$ & $2.5 \mathrm{wt} \%(\mathrm{mPa} \mathrm{s})$ & $3 \mathrm{wt} \%(\mathrm{mPa} \mathrm{s})$ \\
\hline 0.4 & 30 & 31 & 33 & 33.5 & 35 & 36 \\
\hline 0.5 & 36 & 38 & 39 & 40 & 43 & 47 \\
\hline 0.6 & 44 & 45 & 46.5 & 48 & $7.5 \times 10^{4}$ & $9 \times 10^{4}$ \\
\hline 0.7 & 52 & 55 & 57 & $8 \times 10^{4}$ & $10 \times 10^{4}$ & $12 \times 10^{4}$ \\
\hline 0.8 & 61 & 64 & $7 \times 10^{4}$ & $13 \times 10^{4}$ & $14 \times 10^{4}$ & $15.5 \times 10^{4}$ \\
\hline 0.9 & 72 & 75 & $8.3 \times 10^{4}$ & $14 \times 10^{4}$ & $15 \times 10^{4}$ & $17 \times 10^{4}$ \\
\hline 1 & 83 & 86 & $10 \times 10^{4}$ & $14.8 \times 10^{4}$ & $16.5 \times 10^{4}$ & $18 \times 10^{4}$ \\
\hline
\end{tabular}

modification cellulose is too low, the active points offered by modification cellulose are few so that the grafting reaction cannot occur. When the concentration of acrylamide is less than $1 \mathrm{wt} \%$, the gelling solution also cannot be gelled even if the amount of modification cellulose is high. Because when the concentration of acrylamide is too low, the long-chain of polyacrylamide cannot be formed so that the cross-linking reaction between the chain of polyacrylamide and the cross-linking agent cannot occur. However, the gelling solution can form a gel when the concentration of cellulose is more than $0.7 \mathrm{wt} \%$ and the concentration of acrylamide is greater than $2 \mathrm{wt} \%$. The viscosity of the gel is increasing with the increase of the concentration of the main agents. By comparing the viscosity of the gelling solution before and after gelation and its cost, the gelling solution with $0.8 \mathrm{wt} \%$ modified cellulose and $2 \mathrm{wt} \%$ acrylamide is a good system. The viscosity of the gel system is $77 \mathrm{mPa}$ s and $13 \times 10^{4} \mathrm{mPa}$ s before and after gelation, respectively.

\section{The effect of the cross-linking agent on the performance of the gel}

The concentration of modified cellulose, acrylamide and initiator is $0.8,2$ and $0.05 \mathrm{wt} \%$, respectively. The experimental results of the effect of the cross-linking agent on the performance of the gel are shown in Fig. 6. From Fig. 6, it can be observed that the viscosity of the gel is increasing with the increase of the concentration of the cross-linking agent. But when the amount of crosslinker increases to a certain value, the viscosity of the gel remains stable. This is because the frame of the gel has been fixed when the concentration of the main agents is fixed, it has not the benefit of increasing the three-dimensional network structure by continuing to increase the concentration of the cross-linking agent. Therefore, it has the best matching relationship of the concentration of the cross-linking agent and the main agents. From Fig. 6, it shows that $0.1 \mathrm{wt} \%$ cross-linking agent is appropriate for the gel system.

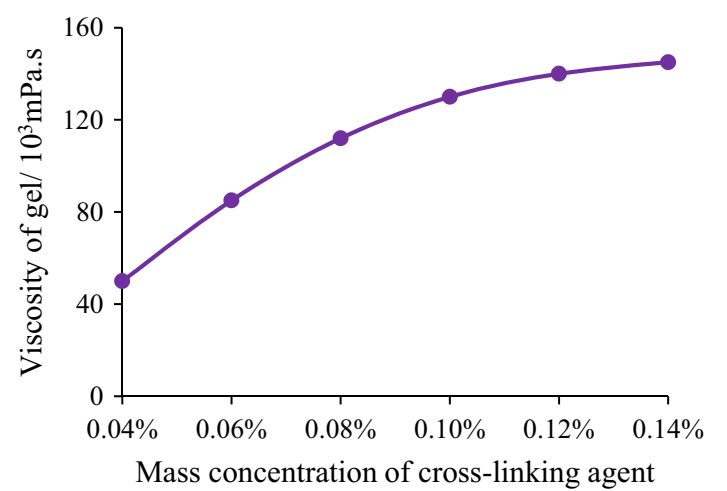

Fig. 6 The effect of cross-linking agent on the viscosity of gel

The effect of the initiator on the performance of the gel

The concentration of modified cellulose, acrylamide and cross-linking agent is $0.8,2$ and $0.1 \mathrm{wt} \%$, respectively. The experimental results of the effect of the initiator on the performance of the gel are shown in Fig. 7. From Fig. 7, it can be observed that the gelation time is decreasing with the increase of the concentration of the initiator. The gelation time is less than $15 \mathrm{~h}$ when the concentration of the initiator is more than $0.05 \mathrm{wt} \%$. When the concentration of the initiator is less than $0.04 \mathrm{wt} \%$, the gelling solution cannot be gelatinized. It shows that the gel system cannot provide enough free radicals to cause the grafting and cross-linking reaction to occur when the concentration of the initiator is too low. So $0.05 \mathrm{wt} \%$ initiator is appropriate for the gel system.

\section{The adaptability of the gel to the environment}

The application range of the gel as a water shutoff agent is decided by its adaptability to the formation environment. The mainly influencing factors of the formation environment on the gel are temperature, salinity and $\mathrm{pH}$ value. In the experiment, each of these three factors is investigated, respectively, to analyze the adaptability of the gel to the formation environment. The gel is consisting of $0.8 \mathrm{wt} \%$ 


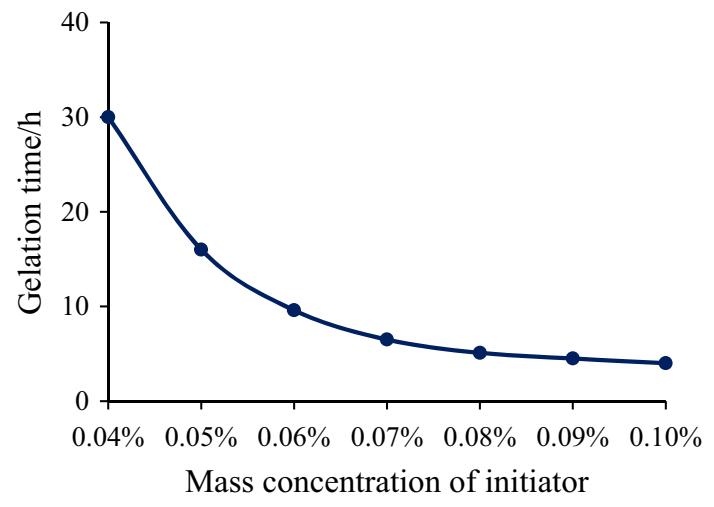

Fig. 7 The effect of the initiator on the gelation time

modified cellulose, $2 \mathrm{wt} \%$ acrylamide, $0.1 \mathrm{wt} \%$ crosslinking agent and $0.05 \mathrm{wt} \%$ initiator.

\section{The effect of temperature on the performance of the gel}

In the experiment, the salinity is $50 \mathrm{~g} / \mathrm{L}$ and $\mathrm{pH}$ value is 7 . The experimental results are shown in Table 3. From Table 3, it can be observed that the gelling solution can form a gel with good performance in the range of 60-90 ${ }^{\circ} \mathrm{C}$. When the temperature is not in the scope of this, the gel cannot be formed or be formed with poor performance. Under low temperatures, the crystal structure of cellulose is completely closed due to the strong hydrogen bonds interactions so that the hydroxyl cannot participate in the graft copolymerization reaction. And the radical polymerization reaction cannot be caused due to the high reaction activation energy. With the increase of temperature, hydrogen bonding of cellulose is weakened and the collision of groups is increasing with the increase of energy so that the reaction can occur and form a gel with good performance. However, when the temperature is too high, the stability of the gel is decreased dramatically. As in the case of $100{ }^{\circ} \mathrm{C}$ in Table 3 , the stable periods of the gel have just 50 days. This is due to the thermal degradation of polyacrylamide chain at high temperatures. So the applicable range of temperature is $60-90{ }^{\circ} \mathrm{C}$.

Table 3 Effect of temperature on the performance of gel

\begin{tabular}{lll}
\hline Temperature $\left({ }^{\circ} \mathrm{C}\right)$ & Viscosity/mPa s & Stable period/day \\
\hline 40 & 65 & - \\
50 & 58 & - \\
60 & $12.5 \times 10^{4}$ & $>220$ \\
70 & $13.0 \times 10^{4}$ & $>200$ \\
80 & $13.3 \times 10^{4}$ & $>200$ \\
90 & $13.5 \times 10^{4}$ & $>180$ \\
100 & $11.8 \times 10^{4}$ & Only 50
\end{tabular}

- , means the gelling solution cannot form a gel so the stable period does not exist
The effect of salinity on the performance of the gel

In the experiment, the temperature is $70{ }^{\circ} \mathrm{C}$ and $\mathrm{pH}$ value is 7. The experimental results are shown in Table 4. From Table 4, it can be observed that the performance of the gel is decreasing with the increase of salinity. When the salinity is $150 \mathrm{~g} / \mathrm{L}$, the gel cannot be formed. With the salinity increase, the electric double layer on the surface of cellulose is compressed so that the crystal structure is wrapped closely, which is bad for the contact of the hydroxyl and free radicals. The result is that the carbon atoms connecting with hydroxyl in the cellulose molecules cannot become the active points so that the reaction of graft copolymerization cannot occur.

\section{The effect of $p H$ value on the performance of the gel}

In the experiment, the temperature is $70{ }^{\circ} \mathrm{C}$ and the salinity is 0 . The experimental results are shown in Table 5. From Table 5, it can be observed that the gel can be formed when the $\mathrm{pH}$ value is $6-9$. When the $\mathrm{pH}$ value is below 6 , the acidic environment can enhance the effect of hydrogen bonding which is unfavorable for reaction, and the acid can damage the structure of the chain of polyacrylamide, so the gel cannot be formed. With the increasing of the alkaline degree, the intermolecular and intramolecular hydrogen bond of cellulose are weaken, which is good for the crosslinking reaction. However, when the alkaline increases to a certain extent, the hydrolysis phenomenon of cellulose molecules occurs, which can reduce the degree of polymerization. This change weakens the support function of

Table 4 Effect of salinity on the performance of the gel

\begin{tabular}{lll}
\hline Salinity $(\mathrm{g} / \mathrm{L})$ & Viscosity/mPa s & Stable period/day \\
\hline 0 & $13.0 \times 10^{4}$ & $>220$ \\
50 & $12.5 \times 10^{4}$ & $>220$ \\
100 & $10.0 \times 10^{4}$ & $>200$ \\
150 & 45 & - \\
\hline
\end{tabular}

Table 5 Effect of $\mathrm{pH}$ value on the performance of gel

\begin{tabular}{lll}
\hline $\mathrm{pH}$ value & Viscosity/mPa s & Stable period /day \\
\hline 4 & 42 & - \\
5 & 43 & - \\
6 & $11.5 \times 10^{4}$ & $>200$ \\
7 & $13.0 \times 10^{4}$ & $>220$ \\
8 & $13.5 \times 10^{4}$ & $>200$ \\
9 & $13.6 \times 10^{4}$ & $>180$ \\
10 & 45 & - \\
11 & 44 & - \\
\hline
\end{tabular}




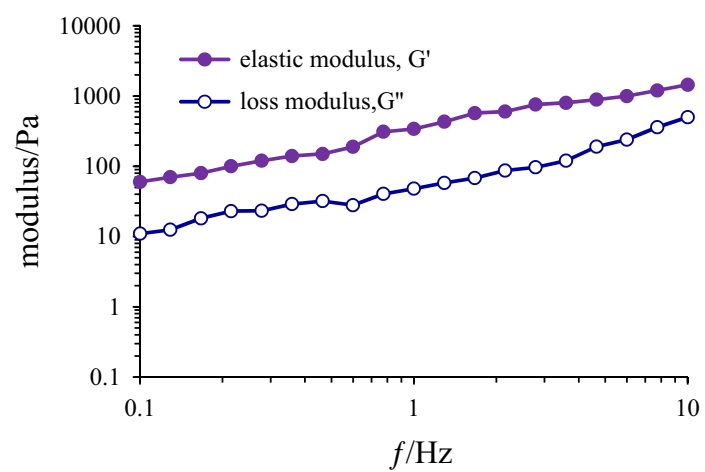

Fig. 8 The visco-elasticity of the gel. The formula of the gel is $0.8 \mathrm{wt} \%$ modified cellulose, $2 \mathrm{wt} \%$ acrylamide, $0.1 \mathrm{wt} \%$ crosslinking agent and $0.05 \mathrm{wt} \%$ initiator

cellulose as the framework in the gel system. And the excessive alkali can lead to the degradation of the polyacrylamide. Although the viscosity of the gel in the weak alkaline environment is slightly high, the stability of the gel is poor. Therefore, the applicable range of $\mathrm{pH}$ value is 6-9.

\section{Performance evaluation of the gel}

\section{Visco-elasticity}

The result of visco-elasticity is shown in Fig. 8. From Fig. 8, it can be observed that both of the elastic modulus and loss modulus of the gel are high. And the elasticity is more outstanding than the viscosity. So the gel has strong plugging ability.

\section{Breakthrough pressure of the gel}

In this experiment, orderly inject pre-pad protection slug, the gelling solution and subsequent protection slug into the core. Other experimental parameters are shown in Table 6. The gelling solution is consisting of $0.8 \mathrm{wt} \%$ modified cellulose, $2 \mathrm{wt} \%$ acrylamide, $0.10 \mathrm{wt} \%$ cross-linking agent and $0.05 \mathrm{wt} \%$ initiator. Measure the breakthrough pressure after $48 \mathrm{~h}$ to ensure that the gel has been formed. The experimental result is shown in Fig. 9. From Fig. 9, it can be observed that the breakthrough pressure of the gel is 2.1 MPa. And the pressure can stably maintain at about $1 \mathrm{MPa}$ after water break through the gel, which show that

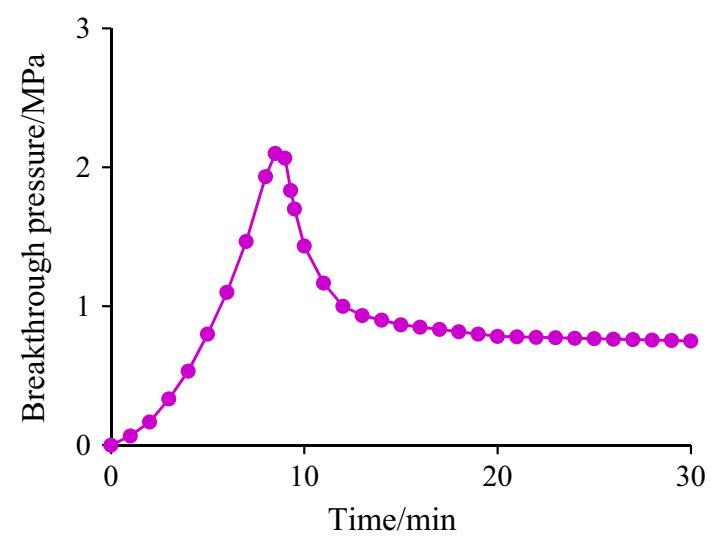

Fig. 9 Breakthrough pressure of the gel

the gel has good residual resistance coefficient. So the gel can plug the high permeability layer to ensure that the subsequent water can displace the oil in the low permeability layer.

The experiment of plugging and enhancing oil recovery

The parameters of heterogeneous core are shown in Table 7 . When the water cut of produced liquid reach to $98 \%$, the gelling solution is injected into the core. After $48 \mathrm{~h}$, the core is flooded again by the subsequent water until the water cut of produced liquid reach to $98 \%$ again. The injection parameters of the gelling solution and the experimental results are shown in Table 8. By comparison of Table 7 and Table 8 , the oil recovery of heterogeneity reservoir is greatly improved when the gelling solution is injected.

\section{Conclusions}

(1) The initial viscosity of the modified cellulose solution is low. It is Newtonian fluid in porous medium and it can migrate into the deep formation. A water-based gel is synthesized by modified cellulose, acrylamide, cross-linking agent and initiator. The gel, comprising of $0.8 \mathrm{wt} \%$ modified cellulose, $2 \mathrm{wt} \%$ acrylamide, $0.1 \mathrm{wt} \%$ crosslinking agent and $0.05 \mathrm{wt} \%$ initiator, has strong viscoelasticity and its elasticity is more outstanding.

Table 6 Parameters of core flow experiment of modified cellulose solution

\begin{tabular}{|c|c|c|c|c|c|c|}
\hline \multirow{2}{*}{$\begin{array}{l}\text { Temperature/ } \\
{ }^{\circ} \mathrm{C}\end{array}$} & \multirow{2}{*}{$\begin{array}{l}\text { Core } \\
\text { permeability/ } \\
\mu \mathrm{m}^{2}\end{array}$} & \multirow{2}{*}{$\begin{array}{l}\text { Core } \\
\text { porosity/ } \\
\%\end{array}$} & \multirow{2}{*}{$\begin{array}{l}\text { Injection rate/ } \\
\mathrm{cm}^{3} / \mathrm{min}\end{array}$} & \multicolumn{3}{|l|}{ Injection fluid } \\
\hline & & & & Pre-pad protection slug & Main slug & Subsequent protection slug \\
\hline 70 & 2 & 25.3 & 2 & $\begin{array}{l}0.1 \mathrm{PV} \text { of } 0.8 \mathrm{wt} \% \text { modified } \\
\text { cellulose solution }\end{array}$ & $\begin{array}{l}0.3 \mathrm{PV} \text { of the } \\
\text { gelling solution }\end{array}$ & $\begin{array}{l}0.1 \mathrm{PV} \text { of } 0.8 \mathrm{wt} \% \text { modified } \\
\text { cellulose solution }\end{array}$ \\
\hline
\end{tabular}


Table 7 Parameters of heterogeneous cores and water flooding

\begin{tabular}{lllll}
\hline Core size $/ \mathrm{cm}^{3}$ & Porosity & Permeability $/ \times 10^{-3} \mu \mathrm{m}^{2}$ & Oil saturation & Water injection rate $/ \mathrm{cm}^{3} / \mathrm{min}^{\text {Oil recovery } / \%}$ \\
\hline $4.5 \times 4.5 \times 30$ & 0.21 & $\begin{array}{l}200 \\
2000\end{array}$ & 0.72 & 2 \\
\hline
\end{tabular}

Table 8 Injection parameters of the gelling solution and the experimental results of plugging

\begin{tabular}{|c|c|c|c|c|c|}
\hline \multicolumn{3}{|l|}{ Injection fluid } & \multirow{2}{*}{$\begin{array}{l}\text { Injection rate/ } \\
\mathrm{cm}^{3} / \mathrm{min}\end{array}$} & \multirow{2}{*}{$\begin{array}{l}\text { Enhanced oil } \\
\text { recovery } / \%\end{array}$} & \multirow{2}{*}{$\begin{array}{l}\text { Ultimate recovery } \\
\text { factor } / \%\end{array}$} \\
\hline Pre-pad protection slug & The main slug & After-pad fluid & & & \\
\hline $\begin{array}{l}0.1 \mathrm{PV} \text { of } 0.8 \mathrm{wt} \% \text { modified } \\
\text { cellulose solution }\end{array}$ & $\begin{array}{l}0.2 \mathrm{PV} \text { of the } \\
\text { gelling solution }\end{array}$ & $\begin{array}{l}0.1 \mathrm{PV} \text { of } 0.8 \mathrm{wt} \% \text { modified } \\
\text { cellulose solution }\end{array}$ & 2 & 12 & 40 \\
\hline
\end{tabular}

(2) The environment that the gel can adapt to is the temperature of $60-90{ }^{\circ} \mathrm{C}$, the salinity of $0-100 \mathrm{~g} / \mathrm{L}$, the $\mathrm{pH}$ value of 6-9. In the neutral environment, the stable period of the gel is the longest. In the alkaline environment, the viscosity of the gel is slightly increasing, but its stability is poor. The gel can plug the high permeability layer to ensure that the subsequent water can displace the oil to enhance the recovery in heterogeneity reservoirs.

Acknowledgments This work was financially supported by the Major National Science and Technology Specific Projects in China (20011ZX05009-004) and the Fundamental Research Funds for the Central Universities in China.

Open Access This article is distributed under the terms of the Creative Commons Attribution 4.0 International License (http:// creativecommons.org/licenses/by/4.0/), which permits unrestricted use, distribution, and reproduction in any medium, provided you give appropriate credit to the original author(s) and the source, provide a link to the Creative Commons license, and indicate if changes were made.

\section{References}

Dai CL, You Q, Zhao FL (2010) In-depth profile control technologies in China-a review of the state of the art. Pet Sci Technol 28(13):1307-1315

Dai CL, You Q, Zhao FL (2011) Study and field application of a profile control agent in a high temperature and high salinity reservoir. Energ Sour A 34:53-63

Hou Y, Yue X (2010) Research on a novel composite gel system for $\mathrm{CO}_{2}$ breakthrough. Pet Sci 7(2):245-250

Jia H, Pu WF (2013) Research on water control and water shutoff technologies of organic-gel. Journal of Southwest Petroleum University (Science and Technology Edition) 35(6):141-152 (in Chinese)

Li Y (1988) Research of TP-910 profile control technology. Oil Drilling Prod Technol 21:179-192 (in Chinese)
Liao Y, Wang S, Luo Z, Zhou J, Yu C, Cen K (2002) Research on cellulose pyrolysis kinetics. Journal of Zhejiang University (Engineering Science) 36:172-176 (in Chinese)

Liu Y, Bai B, Wang Y (2010) Applied technologies and prospects of conformance control treatments in China. Oil Gas Sci Technol 65(6):859-878

Pan S, Song R, Zeng M (1999) Preparation of superabsorbent by grafted copolymerization of acrylic acid onto superfine cellulose. J Cellulose Sci Technol 7:24-27

Peltzer M, Pei A, Zhou Q, Berglund L, Jimenez A (2014) Surface modification of cellulose nanocrystals by grafting with poly (lactic acid). Polym Int 63(6):1056-1062

$\mathrm{Pu}$ W, Hu S, Chen G, Wang Z (1997) Evaluation of water shut of system XN-PP. Drilling Fluid Compl Fluid 14(5):3-7 (in Chinese)

Ren T, Shen B, Li Y, Wan J (2004) The homogeneous reactions of cellulose. Prog Chem 16:948-953

Tang X, Li Y, Cai Z (1996) Water control in production wells by constructing isolating plate of crosslinked polyacrylamide aqueous gels between oil and bottom water layers. Oilfield Chem 13(3):219-223

Tang X, Cai Z, Li Y (1997) An improvement in using in situ gelled acrylamide/methylene-bisacrylamide water shutoff agent. Oilfield Chem 14(2):31-134 (164)

Tehrani A, Neysi E (2013) Surface modification of cellulose nanowhisker throughout graft polymerization of 2-ethyl-2-oxazoline. Carbohyd Polym 97(1):98-104

Thakur V, Thakur M, Gupta R (2013) Graft copolymers from cellulose: synthesis, characterization and evaluation. Carbohyd Polym 97(1):18-25

Vossoughi S (2000) Profile modification using in situ gelation technology-a review. J Pet Sci Eng 26:199-209

Woods P, Schramko K, Turner D, Dalrymple D, Vinson E (1986) Insitu polymerization controls $\mathrm{CO}_{2}$ /water channeling at Lick Creek. SPE paper 14958

Yamada H, Loretz B, Lehr C (2014) Design of starch-graft-PEI polymers: an effective and biodegradable gene delivery platform. Biomacromolecules 15(5):1753-1761

Zhang Y, Li H, Li X, Gibril M, Yu M (2014) Chemical modification of cellulose by in situ reactive extrusion in ionic liquid. Carbohyd Polym 99:126-131 